\title{
Thinking of Doing a Doctorate? Reflections From a Tertiary Learning Advisor Perspective
}

\section{Quentin Allan}

Auckland University of Technology, New Zealand

qallan@aut.ac.nz

\begin{abstract}
This article considers the desirability of the doctorate for a tertiary learning advisor (TLA), explains the process and experience of doctoral study, and affirms how doctoral study can enhance the effectiveness of a TLA in developing students' academic literacies. Effectiveness relates not only to the pedagogical relationship between a TLA and students, but to enhanced visibility and credibility of the TLA and their team within their institution. But what is the doctoral journey actually like? This article will be of interest to curious individuals who may have wondered what the doctorate involves in terms of time and commitment, and whether the benefits outweigh the costs. This article seeks to demystify the process and encourage neophyte researchers who may be considering a qualitative project. Using an autoethnography approach, I take as a case study my own doctoral journey, touching on my initial motivation and sharing candid insights on the challenges and milestones as I perceived them. These insights are shared through a series of brief narratives and reflections, with practical advice offered for each stage of the journey.

Keywords: tertiary learning advisor, TLA, doctoral study, doctorate, $\mathrm{PhD}$, autoethnography
\end{abstract}

This article explores the doctoral journey of a tertiary learning advisor (TLA) currently working at a university in Aotearoa New Zealand. Using an autoethnography approach (as informed by Ellis et al., 2011), I reflect on my recent experiences of completing a PhD at Auckland University of Technology. My target reader is any TLA who is considering doctoral study, especially one involving qualitative data. I have 
endeavoured to write the sort of article that I would like to have read in the early stages of my own journey, a time when I did not clearly understand just what I was letting myself in for. I start by exploring some of the key factors involved in embarking on a doctorate, including motivation, time, and the need for support. Then, using key milestones as a framing device, I outline my own experiences and provide comments about how other TLAs might experience each phase of the doctoral journey, with the objective that others might learn from my experience. ${ }^{1}$

\section{Factors in Deciding to Embark on a Doctorate}

An important motivating factor for me as a TLA was the clear sense that working through the doctoral process would further develop my research and writing skills. When I enrolled, I did not actually need a doctorate, and beyond gentle encouragement from my managers, there was no expectation or pressure to become additionally qualified. According to the most recent survey of TLAs in Aotearoa New Zealand (Cameron, 2018), 61\% of TLAs have a postgraduate qualification, mainly master's degrees, with relatively few doctoral degrees. I enrolled partly because in a competitive academic environment it seemed like a sensible strategic move to add another qualification to my CV. Also, after completing my master's degree I had often thought about further study. However, I was aware that doctoral programmes are plagued with a high attrition rate for a variety of reasons; for example, Carruth (2015) points to unrealistic expectations of the time and effort required, dysfunctional relationships with supervisors, and self-esteem issues such as lack of confidence. Through my career, I have met numerous colleagues - including TLAs - who have started a doctorate, and not completed. I did not want this to be my experience, so I held off applying until I was sure that this was what I wanted to do. I also paid particular attention to logistics such as arranging appropriate study space at home and confirming that my manager and team would be supportive. More experienced colleagues advised me that the value of the doctorate resides largely in the overall experience. I was encouraged to think of the doctorate in terms of an apprenticeship into advanced research techniques: designing the research proposal, conducting the fieldwork, analysing the data, writing up the thesis, and disseminating the findings. So much of my motivation lay in the awareness that if I surrendered to this process, I would develop useful academic skills and grow as a person. 
In terms of advice for a TLA considering doctoral study, my first observation relates to your reasons for enrolling. A sense of could do a doctorate or should do a doctorate is probably not sufficient. The modal verb par excellence is 'must'-you need to feel compelled to complete the research and write up the thesis. Ideally, at some point, the vague possibility of maybe doing a doctorate morphs into a compulsion that cannot be ignored. That is a good time to start.

In terms of your own preparation, a sound investment in the early stages is to explore the terrain first. Consult a range of resources; for example, books (Denholm \& Evans, 2006; Hawley, 2003; Kelly, 2017; Waring \& Kearins, 2011, 2021); articles (Cahusac de Caux, 2021; Frick \& Brodin, 2020; Leshem, 2020), and websites (such as Sage Research Methods [https://methods.sagepub.com] and Thesis Whisperer [https://thesiswhisperer.com]). Broaden your reading to include some of the advice given to research TLAs, doctoral supervisors, and examiners (Carter \& Laurs, 2014, 2018; Denholm \& Evans, 2007; Tinkler \& Jackson, 2004; Wisker, 2012). It is also rewarding to spend time exploring successful theses across a range of disciplines and methodologies in, for example, AUT's Scholarly Commons, Tuwhera Open Access Research Repository (https://tuwhera.aut.ac.nz/research-repository). And, of course, talk to people who have been through the process, especially recently.

You will need to be very clear about the sacrifices necessary in terms of time and resilience needed for this project. However, with careful planning it is possible to rearrange your time so that you juggle work, home life, recreation, and study. Perhaps warn significant others in your life that you may have less availability and emotional energy for a few years. If you can, negotiate with your manager for regular research time throughout. However, as Cameron (2018) notes, not all TLAs are fortunate enough to have contracts that include research time: "Just under $40 \%(\mathrm{~N}=22)$ of those describing themselves as research active had a formal time allowance" (p. 38). Without an agreed reduction in working hours, time management becomes even more critical. If you consider the doctorate as a full-time 40 -hour job - or 20 hours part time-then where will this time come from? Ideally you arrange your life to do the study full time, but for most TLAs, this simply is not possible. However, it is quite possible to juggle work and study, and complete the doctorate part time in four or five years. It helps if you maintain a sense of constant forward motion- even in times of low energy, 
spending just 10 minutes a day (perhaps for trivial administration jobs) will help to keep the project moving.

The final factor to consider when contemplating a doctorate is support. Before you commit, it is in everyone's interests that you initiate a frank discussion with your nearest and dearest to explore the practical and emotional support you will require. Another primary mode of support comes from your supervisors. It is important to ensure that you will be able to work constructively together; as part of your due diligence, you might make some preliminary enquiries, perhaps asking previous and current candidates about their experience of supervision with particular individuals. Each institution will have its own mechanism for arranging an appropriate supervisory team. In my case, rather than waiting to have a supervisor assigned to me, I took the initiative of asking my colleagues whom they would suggest, and when the same name recurred (of a highly experienced supervisor and doctoral examiner), I approached this person with an outline of my proposed research ${ }^{2}$. After an hour's discussion, I asked if she would be interested in supervising the project. Her positive response was hugely encouraging, and we then discussed possibilities for a second supervisor-again, a senior academic with a great deal of experience. Finding a good fit between candidate and supervisors is critical to both an enjoyable study dynamic and a positive outcome in terms of completion (Manalo \& Trafford, 2004).

In terms of wider support, take time to identify all the mechanisms available to you in your institution. These include technical advice (for example, with data management software such as SPSS [quantitative] or NVivo [qualitative], and bibliographic management systems), and assistance in managing long documents and editing. Information literacy guidance from specialist liaison librarians is invaluable, especially when approaching the literature review. Even though as TLAs we are well placed in terms of our own expert understanding of text structure and argumentation, it is always helpful to enlist the expertise of a specialist postgraduate TLA for advice (Laurs, 2018). It helps to talk to as many people as you can about your study, both before starting, and as you are doing it - anyone who shows genuine interest. Recall that heartening refrain from Paulo Coelho's 2004 novel, The Alchemist: "When you want something, all the universe conspires in helping you to achieve it" (p. 22). It was certainly my experience that help and support came from many unexpected quarters. 
Proactivity is good: setting up or engaging in communities of practice with other doctoral students is invaluable (Lave \& Wenger, 1991). The friendships you make during this time will run very deeply, and endure long after the graduation ceremony. A learning journal is useful to systematically examine complex ideas, work through areas of bewilderment and frustration, plan workflow and outputs, and track progress through the ups and downs. I started keeping a learning journal when I first contemplated embarking on a doctorate, and it continued to be a practical tool to refer to when writing up themes for publication, including the article you are reading. This journal was one of the most important mechanisms of the whole process, and I cannot recommend it highly enough.

\section{Key Milestones}

While each institution will have their own requirements or formal process for students completing a doctorate, there will be some common milestones and generic experiences, as indicated in Figure 1.

\section{Figure 1}

Common Milestones in the Doctorate

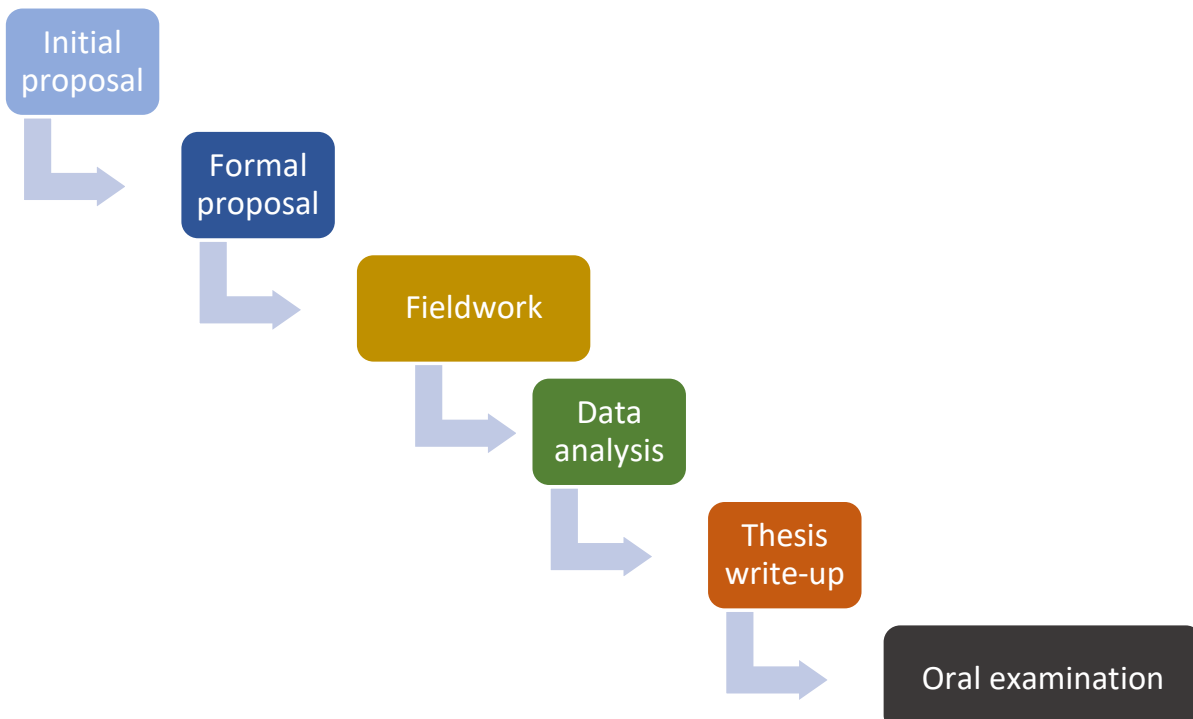




\section{Initial Proposal}

In order to be accepted onto a doctoral programme, you will be required to submit a brief proposal indicating the topic, the working title, your rationale for the study, an indication of the likely significance, research aims and objectives, an indicative survey of the literature, and, as a preface to the proposed research design and ethical considerations, an outline of your paradigmatic positioning. For me, one memorable challenge was reducing my ideas to just a few thousand words; another was articulating my paradigmatic positioning. But first, I had to find a topic.

\section{Choosing a Topic}

When choosing a topic, there are three salient questions to consider: What subject area? What discipline? How to express the topic succinctly? From my reading, I was aware that a key criterion for success was finding the right topic. In terms of cost and time, the commitment had to make sense; if I was going to devote four or five years of my life to this project, then it was important to examine a sociological or pedagogical issue that would be meaningful and of interest to a wide variety of people. So, what might be a suitably engaging issue for me to explore? In terms of the discipline of learning advising, linguistics or education presented as obvious contenders, and I considered many possibilities; however, nothing struck me as absolutely compelling. As I saw it, a research question such as the one I pursued for my MA in applied linguistics — relating to periphrastic syntactic strings of a canonical type (Allan, 1994) might absorb me, but would have very little interest for most people, including TLA colleagues. As it happened, my university was prepared to support my research on any theme that I proposed and could find a supervisor for. I was fortunate: such freedom is not common in all tertiary institutions.

And then one day, an epiphany struck as I was perusing the morning paper and happened to read two articles about homophobia. As a gay man I had noticed that despite the significant homosexual law reforms of the 20th century, evidence of residual homonegativity manifested in diverse ways, including people delaying the disclosure of their gay identity. This sociological phenomenon suggested itself as a compelling focus for doctoral research, and the working title of my thesis became: 'Gay men coming out later in life'. Fortunately, my university at that time was supportive of this topic; increasingly, however, institutions require TLA doctoral candidates to confine their 
research to pedagogical or linguistic topics. In any case, for a TLA considering doctoral research, finding the right topic is critical, and not something that can be rushed. Useful strategies include talking to a diverse range of colleagues and keeping a notebook of possibilities.

\section{Articulating Your Paradigmatic Positioning}

Your paradigmatic positioning is a consideration of how you propose to align your research project with your world view. This requires you to articulate your understanding of the nature of reality (ontology), then consider theories of knowledge, or ways of accessing reality (epistemology).

Two years before I enrolled, when I first encountered the term 'paradigmatic positioning', I sensed that I might be wading into murky waters. What did these words actually mean? The terms seemed familiar enough, but as I attempted to craft a response, I realised that I was out of my depth. And so I resorted to a familiar strategy: Google. My searches threw up results that were frankly bewildering, and not immediately helpful - a jumble of unfamiliar terms such as ontology, grounded theory, interpretivism, phenomenology, epistemology, positivism. In order to make sense of this bamboozling array of new concepts I read numerous books and articles on research methods. I found the following resources particularly helpful: Crotty (1998), Grant and Giddings (2002), and Creswell (2007). The reading associated with approaches to research is intellectually stimulating, even entertaining. For example, I enjoyed learning about the 'Paradigm Wars' of the late 20th Century (Feyerabend, 1993; Kuhn, 1970), discovering the possibilities of indigenous epistemologies (Smith, 2012), and delving into non-traditional approaches (Engels-Schwarzpaul \& Peters, 2013). To complement my reading, I consulted with colleagues, and signed up for a research methods master class run by one of the health science professors whose practical orientation helped me to make sense of the various labels. A turning point for me was the moment when I realised that research frameworks could be usefully organised under three broad epistemological headings: objectivism, subjectivism, and constructivism (Crotty, 1998). Constructivism appeared to be an appropriate fit for my sociological inquiry,. According to Crotty (1998), constructivism foregrounds the importance of the researcher perspective, emphasising "the meaning-making activity of the individual mind" (p. 58). In particular, I liked that constructivism recognises the influence of 
disciplinary discourse and is suspicious of the notion of 'truth', or 'objective' knowledge. At Crotty's 'theoretical perspective' level, under the heading of Constructivism, is 'Interpretivism', where the emphasis is on "culturally derived and historically situated interpretations of the social life-world" (Crotty, 1998, p. 67). As I worked through the materials, and mapped out my ideas, I found that simply being able to understand and articulate these key concepts provided me with huge confidence.

For the success of your project, you need to establish a solid theoretical foundation on which to build your research. When you are faced with the challenge of having to articulate your paradigmatic positioning, a useful starting point might be to pose the question 'Why me, and why this topic?' (Davis, et al., 2021). You will need to draw from this knowledge at various stages throughout the doctorate; for example, in defending your paradigmatic positioning during the oral examination.

\section{Methodology/Methods}

Having decided how your research project aligns with your world view, the next step is to select an appropriate methodology (theoretical perspective, or rationale for employing particular methods), and then to identify the actual methods you propose to employ (Creswell, 2007; Clough \& Nutbrown, 2012). In my case, after about a year of reading widely and considering the various methodological possibilities (including narrative enquiry, grounded theory, and critical discourse analysis), I realised that hermeneutic phenomenology would be the most appropriate lens through which to explore the lived experience of my participants. This approach has at its heart a concern with uncovering unexamined aspects of ordinary, every-day life. Despite initial concerns that the approach appeared somewhat unstructured, I discovered here a seductive and powerful methodology, one that has tremendous transformative potential, both at an individual and societal level (Gadamer, 1975/2013; Heidegger, 1953/2010; van Manen, 2014). This choice of methodology was the conclusion that my supervisors were patiently waiting for me to reach in my own time. On reflection, I am extremely grateful to them for having given me the intellectual space to explore the various options and arrive at this decision myself. For a TLA pursing doctoral study, the value of considering a range of possibilities is twofold: first, in anticipation of the oral examination, you can expect to be asked what other methodologies you have considered, and your rationale for having chosen one above the others; second, as a 
TLA, familiarity with a range of approaches will enhance your ability to work with postgraduate research students, including doctoral supervision.

\section{Ethics Application}

One major aspect of any research project involving human or animal participants is the application for ethics approval. Working through this process was a novel experience for me. It took far longer than I envisaged, and frankly, at first I felt that this requirement was somewhat over the top. However, after engaging with the literature, I developed a heightened awareness of the need for a robust mechanism, especially after reading about the "Unfortunate Experiment" (the lack of ethics in research involving cervical cancer at National Women's Hospital in Auckland, exposed by an investigative reporter in 1987 [Coney, 1988]). Any research involves a careful consideration of the ethics involved, and the work that goes into drafting an ethics proposal is considerable. If you are considering qualitative research, you can anticipate having to articulate your motivation, paradigmatic positioning, precise research questions, inclusion and exclusion criteria for participants, and potential psychological harm to participants and researcher. The effort involved in developing a robust ethics application will be amply rewarded as much of the content is likely to find its way into your thesis, and the thinking required will certainly help to focus your research.

\section{Confirmation of Candidature Process (Formal Proposal)}

This is a major milestone, and each institution will have its own approach. You can expect the following components as part of the process: you first prepare a formal written proposal (approximately 10,000 words), which is submitted to reviewers either internal or external, or a combination; you will then be required to present a summary of the proposal in a seminar at which further questions from the reviewers will be asked. The audience - which typically includes your supervisors and a group of supportive friends and colleagues - may be invited to comment, or ask probing questions, all designed to provide collegial support and constructive advice. After the seminar, the reviewers will confer, and soon after, the outcome is communicated to the candidate: ideally you will be confirmed in your candidature, or if the proposal requires further work, then constructive advice will be provided and a timeline indicated. 
In order to prepare effectively, it is desirable for you as a prospective candidate to engage with a scholarly community of practice, both to observe other candidates practise presenting their proposals (followed by a systematic deconstruction), and to do your own trial run with feedback. If no such group exists in your institution, I suggest you proactively form such a community. I was fortunate to be able to do a practice run of my presentation with a supportive group of other doctoral candidates - members of AUT's 'potluck' seminar group run by my primary supervisor, as recounted in Waring and Kearins $(2011,2021)$. This group proved to be an important and enduring community of practice, and throughout my candidature I looked forward to the monthly gatherings as an intellectual highlight. My formal proposal took about a year to prepare, and the time invested paid considerable dividends in terms of clarity of thinking and useful text generated.

\section{Fieldwork}

For a qualitative research project such as this, an important component is going out 'into the field' to gather interview data. In anticipation of fieldwork, I read practical guides such as Hutching (2004) and undertook training in oral history interviewing techniques offered through the National Library. This hands-on course provided guidance in preparation, including development of logistical checklists, and familiarisation with audio recorders and transcribing software. It also provided opportunities to practise interviewing and to experience actually being interviewed. Each simulation was followed by professional debriefings and round-table discussions to explore issues emerging, and to identify best practice. Before meeting with any of the participants, I followed the advice of my supervisors and conducted a pilot interview on myself. This experience made me more attuned to the specialised dynamics of interaction in an interview, and at a practical level, helped me to rework the order of questions, to amend confusing items, and remove non-productive questions. A major objective for me in setting up the interviews was building solidarity, so one or two weeks before each interview I arranged to meet for 'a cup of tea' and a familiarisation chat. This meeting provided an opportunity for participants to ask questions and clarify any issues or concerns. In terms of epistemological solidarity, it proved to be an ideal time to share personal stories, identify common experiences, and establish a cordial working relationship. Establishing trust is essential for generating rich qualitative data. 
In my case, it helped that as a gay man, I would be seen by my research participants as an insider.

Preparing for interviews is logistically challenging, and this process is likely to generate copious amounts of data that will need secure file management systems; for example, your ethics committee is likely to insist that hard copies of confidential documents be stored in a locked cabinet. For the interviews you might generate checklists, then assemble hard copies of information sheets, and permission slips in labelled plastic folders (one for each participant); each permission slip needs to be scanned and saved, then backed up in a secure location. Tedious as this preparatory phase may be, taking the trouble to be well organised means that the interviews will proceed smoothly. The experience of 'going into the field' is likely to stand out for you as one of the most rewarding aspects of the entire project. As you start hearing the testimony of your participants, you become acutely conscious of the trust placed in you, and the responsibility you have to do justice to whatever it is you are researching. You should not hurry the process. Resolve to take as long as is necessary for your participants to share their stories, and that means re-setting your 'rushometer' as there is no place for haste if quality research is the goal. Time needs to slow down. And so, for each research interview, make a conscious effort to decelerate; aim to be truly present. Focus on what is actually happening in the interview, and do not allow yourself to be distracted by thinking about emergent themes, or other aspects of analysis - that can happen later. Take time to write up your field notes as soon as possible after the interview. In practical terms, this may involve simply parking your car around the corner to jot down ideas while they are fresh, or, more ideally, finding a café where you can sit quietly for an hour or so noting your observations of the interview space, and reflecting on what you have noticed during your interaction. These field notes will become a valuable resource a year or so later when you might have forgotten particular aspects of each interview. Schedule time to listen to each interview once through, simply dwelling in the audio, and not distracting yourself with the mechanics of transcribing. Instead of paying for a professional transcriber, consider polishing up your touch-typing skills and be prepared to put in the long, slow, necessary hours at the keyboard. Rather than conceiving of this as a chore to be completed, relish the 
opportunity to engage with the research data-you will become increasingly familiar with the emerging themes, salient narratives, and interpretive possibilities.

\section{Data Analysis and Writing up the Thesis}

While Figure 1 suggests the data analysis phase and the writing up of a thesis are discrete tasks, they are not-indeed, there is considerable overlap. It is helpful to consider the approach as rhizomatic: organic and constantly evolving. In terms of file management on my computer, at the very start of the project I found it helpful to set up separate folders for each chapter of the thesis. Each folder functioned as a repository for relevant documents and resources; for example, the literature review folder contained my draft chapter, my search diary (Hart, 2001), a reading synthesis grid (an Excel spreadsheet), and the critiquing tools I had adapted from Hart (1998, 2018).

The writing is likely to start with your first tentative attempts to put together a proposal, and over four to five years you may add, develop, finesse, and subsequently discard bits and pieces from your proposal, your ethics application, your journal, your field notes, and your analysis. This is one of the more challenging aspects of the doctorate - spending considerable amounts of time and energy developing text, only to find yourself ruthlessly discarding it because it proves to be repetitive or redundant. After devoting an appropriate amount of time analysing your data, the drafting of the thesis will become your primary focus. Your thesis-writing world will narrow to a round of thinking, drafting, revising, and editing. This is a critical time where you need time and space to write, so if you are able to negotiate longer chunks of leave, this is a good time to do so.

\section{Oral Examination (and Revision of Thesis)}

At an appropriate time, the supervisors will submit the thesis for examination. The examiners (typically one internal, and one external) are acknowledged experts in either the discipline or the methodology. The examiners will read the thesis carefully and provide a written report. The examiners (in New Zealand universities) will then question the candidate during a formal oral examination.

The primary purpose of the oral examination is to ensure that the candidate being examined actually wrote the thesis and can articulate their original contribution; a secondary purpose is to provide an opportunity for the candidate to discuss the research 
and findings with experts in the field (Tinkler \& Jackson, 2004). In practice, most candidates are likely to pass the examination, for the simple reason that their supervisors are unlikely to put them forward if there are any concerns about the likelihood of success (Discover PhDs, n.d.). The examination has four possible outcomes: 'pass with no changes' (rare); 'pass subject to minor emendations' to the satisfaction of the primary supervisor (most common); 'pass subject to major amendments' (for example, rewriting a chapter) to the satisfaction of the examiner (less desirable); or the dreaded 'revise and resubmit'. The inevitable revision phase is not to be feared: Rather, I suggest you see it as a valuable opportunity for further tweaking, informed by editorial input from your examiners (two highly esteemed experts who are encountering your research with fresh eyes), and as an opportunity to reinstate some of the precious text that you previously removed due to concerns about word limit.

In anticipation of the oral examination, I offer three useful pieces of practical advice. The first is to familiarise yourself with the topography of the thesis. I suggest the following process:

- $\quad$ get some blank A4 paper,

- $\quad$ rule each page into two columns,

- $\quad$ on each line write down the page number (column 1 first, then column 2, etc), and

- $\quad$ beside each page number write down the key point of that page in the thesis.

You may also want to put coloured post-it notes on various pages of the thesis.

Following through this process means that you will be intimately acquainted with your thesis by the time you walk into the examination room, and you may find that you only open the thesis once to find a quote. The rest will be in your head.

The second piece of advice is to do a dummy run with your community of practice or other supportive group, anticipating the actual questions from the examiners' report that you receive a week before the oral examination. Then, if you have prepared well, you can enjoy the discussion, and look forward to the moment when you hear yourself being congratulated with your new title.

The final piece of advice is to anticipate the oral examination as a positive, enjoyable experience, and to observe how at a certain point it morphs into a 
conversation between equals, and an opportunity to discuss publication possibilities. If you have conducted the research yourself, and written the thesis, and if your supervisors are happy with your work, you are likely to have a positive experience-so it is helpful to approach the oral examination in a confident frame of mind.

I followed all of the good advice that I had received, and, usefully, had arranged a week of annual leave in order to give myself space and time to prepare. On the morning of the oral examination, I woke up feeling ebullient: looking forward to the experience, secure in having prepared thoroughly, and confident that I knew my thesis well. A more comprehensive reflection on my oral examination, along with an exploration of a diverse range of others' experiences, is available in Allan (2021).

\section{Dissemination of Findings}

Dissemination is important, and as you progress through the doctorate, it is in your interest to anticipate this final phase and prepare place-holder documents. For academic readership, you could map out possible conference presentations and journal articles on various themes and findings; for a non-academic readership, you could consider re-writing the thesis as a book. From a TLA perspective, the experience of presenting at conferences and writing for publication will enable you to provide more effective support for students and colleagues who seek help with these experiences.

I was determined to ensure that as many people as possible would read my thesis, as I had invested so much time and energy on this project and was conscious of the need to get my findings out into the communities where they were most needed. Therefore, as soon as the thesis had been loaded into Tuwhera, AUT's Scholarly Commons, I scheduled time to identify prominent people in various organisations, including government, and systematically sent targeted recipients a carefully crafted explanatory email and a link to the thesis (Allan, 2017). Some replied with affirming responses, and assurances that they would in turn pass the link on; many ignored the email; and others replied angrily at having been contacted. My objective was to ensure that as many people as possible were made aware of my findings and recommendations. In addition, I made myself available for media interviews, and was interviewed by a number of journalists (including Jesse Mulligan on National Radio, Wendyl Nissen on Radio Live, and Laine Moger for Sunday Star Times) soon after the thesis became 
publicly available. My efforts to raise awareness appear to have been worthwhile; for example, I have received encouraging feedback from prominent members of various organisations, including Christian churches. In terms of readership, I am gratified to note that the thesis has been downloaded 4,773 times at the time of writing.

\section{Doctoral Study: Enhancing the Effectiveness of a TLA}

Attempting a doctorate is not without costs. These may include financial hardship, time away from family and leisure pursuits, constant stress from the relentless need to generate text, frustration at being blocked, and occasional reminders of the high stakes nature of the enterprise. Yet it is clear that successful completion yields certain rewards - not least, enhancing your effectiveness as a TLA. The lived experience of doctoral study will help you to operate more empathetically. For example, it will provide you with heightened understanding of many of the challenges faced by students, such as having to grapple with new concepts (feeling lost at times, perhaps making startling new discoveries); juggling multiple complex tasks and constantly meeting the expectations of demanding supervisors; and then submitting written work for a highstakes examination. Another way that a doctorate can enhance your effectiveness as a TLA is that your response to any given teaching situation (including embedded or generic teaching, and consultations with individual students about both coursework and postgraduate research) will more likely include a more mindful appreciation of theoretical, epistemological, and disciplinary possibilities.

As a recent student, you will also have nuanced insights into the psychological and interpersonal elements relating to the teaching dynamic. Doctoral study has numerous other benefits for TLAs; for example, the process of following a complex research project through a series of stages will add to your skill set (improved time management is one likely outcome, ICT proficiency another). Furthermore, the process of crafting a thesis of 100,000 words will encourage you to think even more carefully about the intricacies of academic text, in terms of options for and logistics of execution. All of these considerations combine to make you more effective as a TLA. 


\section{Conclusion}

Studying for a doctorate should be fun, but you can also anticipate an emotional roller coaster, and expect to experience a feeling of disequilibrium after completion. For me, the sense of loss after completing my thesis was unexpected and unnerving: Having spent so many years engaged with such an intense focus on this project, life after completion felt strangely empty for a while. Savour each moment - it is over before you know it.

I was recently asked by a colleague if I were glad to have done a $\mathrm{PhD}$. I reflected for just a moment and then replied, "most definitely". Considering both the financial costs and encroachment into personal time, and notwithstanding the inevitable challenges (intellectual, logistical, and psychological), the enterprise has been well worthwhile. Embarking on the doctoral journey sets in motion a chain of learning that extends far beyond the focus of the research itself. From a personal perspective, the process of having read widely and deeply on an area of interest has expanded my intellectual horizons and enhanced my capacity for critical thinking. On an interpersonal level, I am extremely blessed to have met so many interesting people in the course of this study.

Perhaps this article can be seen as a conversation starter: for a long time, TLAs have felt misunderstood and undervalued by many of their academic colleagues. Given that the doctorate is a rite of passage for academics, surely it is in the interest of the TLA profession for as many practitioners as possible to have a doctorate. This credential enhances your credibility as a member of a highly performing team and increases the visibility of that team in your institution. 


\section{References}

Allan, Q. (1994). A study of the delexical verbs 'give', 'have', 'make' and 'take' from a corpus of academic texts [MA thesis]. University of Birmingham.

Allan, Q. (2017). Gay men coming out later in life: A phenomenological inquiry into disclosing sexual orientation in Aotearoa New Zealand [ $\mathrm{PhD}$ thesis]. Institute of Public Policy, Auckland University of Technology. http://aut.researchgateway.ac.nz/handle/10292/11004

Allan, Q. (2021). Rite of passage: Your oral examination. In M. Waring \& K. Kearins (Eds.), Thesis survivor stories: Practical advice on getting through your PhD or Masters thesis (2nd ed.). Bridget Williams Books.

Cahusac de Caux, B. (2021). Doctoral candidates' academic writing output and strategies: Navigating the challenges of academic writing during a global health crisis. International Journal of Doctoral Studies, 16, 291-317. https://doi.org/10.28945/4755

Cameron, C. (2018). Tertiary learning advisors in Aotearoa/New Zealand: Part one: Building a profile of our profession. ATLAANZ Journal, 3(Special Issue: Identify and Opportunity). https://journal.atlaanz.org/index.php/ATLAANZ/issue/view/4

Carter, S. \& Laurs, D. (2014). Developing generic support for doctoral students: Practice and pedagogy. Taylor \& Francis Group.

Carter, S., \& Laurs, D. (2018). Developing research writing: A handbook for supervisors and advisors. Routledge. https://ebookcentral.proquest.com/lib/AUT/detail.action?docID $=4941868$

Carruth, G. D. (2015). Doctoral student attrition: A problem for higher education. The Journal of Educational Thought (JET) / Revue de la Pensée Éducative, 48(3), 189. https://www.jstor.org/stable/24894120

Clough, P. \& Nutbrown, C. (2012). A student's guide to methodology: Justifying enquiry. Sage.

Coelho, P. (2004). The alchemist. Harper Collins.

Coney, S. (1988). The unfortunate experiment. Penguin Books.

Creswell, J. W. (2007). Qualitative inquiry and research design: Choosing among five approaches (2nd ed.). Sage Publications. 
Crotty, M. (1998). The foundations of social research: Meaning and perspective in the research process. Allen \& Unwin.

Davis, L. M., Tumursukh, U., \& Allan, Q. (2021). Truth about researching truth. In M. Waring \& K. Kearins (Eds.), Thesis survivor stories: Practical advice on getting through your PhD or Masters thesis (2nd ed.). Bridget Williams Books.

Denholm, C., \& Evans, T. (Eds.). (2006). Doctorates downunder: Keys to successful doctoral study in Australia and New Zealand. ACER Press.

Denholm, C., \& Evans, T. (Eds.). (2007). Supervising doctorates downunder: Keys to effective supervision in Australia and New Zealand. ACER Press.

Discover PhDs. (n.d.). PhD failure rate: A study of 26,076 PhD candidates. https://www.discoverphds.com/advice/doing/phd-failure-rate

Engels-Schwarzpaul, T., \& Peters, M. (Eds.) (2013). Of other thoughts: Non-traditional ways to the doctorate: A guidebook for candidates and supervisors. Sense Publishers.

Ellis, C., Adams, T. E., \& Bochner, A. P. (2011). Autoethnography: An overview. Historical Social Research / Historische Sozialforschung, 36(4), 273-290. https://www.jstor.org/stable/23032294

Feyerabend, P. (1993). Against method: Outline of an anarchistic theory of knowledge. Verso.

Frick, B. L., \& Brodin, E. M. (2020). A return to Wonderland: Exploring the links between academic identity development and creativity during doctoral education. Innovations in Education and Teaching International, 57(2), 209219. https://doi-org.ezproxy.aut.ac.nz/10.1080/14703297.2019.1617183

Gadamer, H.-G. (1975/2013). Truth and method (J. Weinsheimer \& D. Marshall, Trans.). Bloomsbury Academic.

Grant, B. M., \& Giddings, L. S. (2002). Making sense of methodologies: A paradigm framework for the novice researcher. Contemporary Nurse, 13(1), 10-28.

Hart, C. (2001). Doing a literature search: A comprehensive guide for the social sciences. Sage Publications.

Hart, C. (1998). Doing a literature review: Releasing the social science research imagination. Sage Publications. 
Hart, C. (2018). Doing a literature review: Releasing the social science research imagination ( $2^{\text {nd }}$ ed.). Sage Publications.

Hawley, P. (2003). Being bright is not enough: The unwritten rules of doctoral study.

C.C. Thomas.

Heidegger, M. (1953/2010). Being and time (J. Stambaugh, Trans.). State University of New York Press.

Hutching, M. (2004). The distance between voice and transcript. In A. Green \& M. Hutching (Eds.), Remembering: Writing oral history (pp. 168-177). Auckland University Press.

Kelly, F. J. (2017). The Idea of the PhD: The doctorate in the twenty-first-century imagination. Taylor \& Francis Group.

Kuhn, T. (1970). The structure of scientific revolutions. The University of Chicago Press.

Laurs, D. (2018). The role of tertiary learning advisors in successful doctoral completion. In S. Carter \& D. Laurs (Eds.), Developing research writing: A handbook for supervisors and advisors (pp. 43-45). Routledge.

Lave, J., \& Wenger, E. (1991). Situated learning: Legitimate peripheral participation. Cambridge University Press.

Leshem, S. (2020). Identity formations of doctoral students on the route to achieving their doctorate. Issues in Educational Research, 30(1), 169-186. http://www.iier.org.au/iier30/leshem.pdf

Manalo, E., \& Trafford, J. (2004). Thinking to thesis: A guide to graduate success at all levels. Pearson Longman.

Smith, L. T. (2012). Decolonizing methodologies: Research and indigenous peoples. Zed Books.

Tinkler, P., \& Jackson, C. (2004). The doctoral examination process: A handbook for students, examiners and supervisors. Society for Research into Higher Education \& Open University Press.

van Manen, M. (2014). Phenomenology of practice: Meaning-giving methods in phenomenological research and writing. Left Coast Press, Inc.

Waring, M., \& Kearins, K. (2011). Thesis survivor stories: Practical advice for getting through your PhD or Masters thesis. AUT Media. 
Waring, M., \& Kearins, K. (Eds.). (2021). Thesis survivor stories: Practical advice on getting through your PhD or Masters thesis (2nd ed.). Bridget Williams Books.

Wisker, G. (2012). The good supervisor: Supervising postgraduate and undergraduate research for doctoral theses and dissertations. Palgrave Macmillan.

\footnotetext{
${ }^{1}$ I would like to acknowledge two colleagues who were kind enough to read through an early draft of this paper and provide valuable editorial advice: Robyn McWilliams and Annabelle Perera. I would also like to acknowledge the peer reviewers whose thoughtful suggestions moved me to reframe the article, moving from a merely reflective piece to focus on practical advice; naturally I take full responsibility for the final version.

${ }^{2}$ I would like to acknowledge my supervisors: Professor Dame Marilyn Waring and Professor Welby Ings.
} 